\title{
COMPETITION BETWEEN COMPATIBLE NUCLEI IN THE ESTABLISHMENT OF A DIKARYON IN SCHIZOPHYLLUM COMMUNE.
}

\author{
LESLIE K. CROWE \\ Department of Botany, Oxford University
}

Received 18.v.63

\section{INTRODUCTION}

THE results of matings between dikaryotic and monokaryotic strains (dimon matings) have been studied in a number of species in the Basidiomycetes including Schizophyllum commune. This fungus has a typical tetrapolar incompatibility system governed by two, unlinked, multiple allelic factors, A and B. Dikaryons are established only by nuclei carrying different $\mathrm{A}$ and $\mathrm{B}$ factors, e.g. $\mathrm{A}^{x} \mathrm{~B}^{x}+\mathrm{A}^{y} \mathrm{~B}^{y}$. $\mathrm{A}$ dikaryotic mycelium with this genotype may be mated with a monokaryotic strain $\mathrm{A}^{z} \mathrm{~B}^{z}$. This is a compatible dimon mating, so called because both nuclei present in the dikaryon are capable of producing a new dikaryon with $\mathrm{A}^{z} \mathrm{~B}^{z}$. Thus, from such a mating the two new dikaryons $\mathrm{A}^{x} \mathrm{~B}^{x}+\mathrm{A}^{z} \mathrm{~B}^{z}$ and $\mathrm{A}^{y} \mathrm{~B}^{y}+\mathrm{A}^{z} \mathrm{~B}^{z}$ can be isolated.

From some compatible dimon matings the two new dikaryotic genotypes are recovered with equal frequency, as might be expected a priori. From other such matings there is a marked preponderance of one class of dikaryon in relation to the other. Kimura (1958) investigated the causes of this inequality in the numbers of the two classes of dikaryon in Coprinus macrorhizus. He found cytoplasmic relationships to be the immediate cause. More recently results from three different replicate series of dimon matings in $S$. commune (Crowe, 1960) gave some indication that the incompatibility factors involved might also influence the ratios.

The bipartite structure of the A and B factors in $S$. commune has been described by Raper et al. (1958). The two sub-units of which each incompatibility factor is composed are themselves multiple allelic and $\mathrm{A}$ and $\mathrm{B}$ factors which differ in one or both of their constituent alleles are compatible. Raper and Ellingboe (I 962 ) have already shown that in compatible dimon matings, selection favouring recovery of one new dikaryon in preference to the other depends to some extent on the B factors. A new dikaryon which is doubly heterozygous in respect of the two alleles in its $B$ factors appears to have an advantage in comparison with a dikaryon in which the alleles of the B factors are singly heterozygous. Thus, a compatible dimon mating in which the factors are $\left(\mathrm{B}_{1-1}+\mathrm{B}_{2-2}\right) \times \mathrm{B}_{1-3}$ * would yield the new genotype $B_{2-2}+B_{1-3}$ more often than $B_{1-1}+B_{1-3}$. Genes other than the incompatibility factors also alter the proportions in which alternative new

* The individual alleles of the $B$ factors are indicated by subscript numbers. Different $B$ mating types are represented by superscript numbers. 
dikaryotic genotypes are recovered. Influence of A factors on the results is not demonstrated in this work. The purpose of the experiments described in this paper is to examine the effects of the $\mathrm{A}$ factors on the results obtained from compatible dimon matings.

\section{MATERIALS AND METHODS}

The stocks used in the course of these experiments are listed in table r. By appropriate crosses other required genotypes were produced.

\section{(i) Production of isogenic strains}

By reason of its breeding system, the different strains of $S$. commune are certainly heterozygous in many respects. In order to be rid of unpredictable effects caused by this heterozygosity, each stock listed in table $I$ was crossed with strain 845 to

TABLE I

Stocks of S. commune

\begin{tabular}{|c|c|c|c|}
\hline Stock no. & $\begin{array}{l}\text { Incompatibility } \\
\text { factors }\end{array}$ & $A$ alleles & $\mathrm{B}$ alleles \\
\hline $\begin{array}{r}73 \\
32 \\
699 \\
751 \\
1058 \\
837 \\
844 \\
845\end{array}$ & $\begin{array}{l}A^{8} B^{2} \\
A^{9} B^{9} \\
A^{41} B^{41} \\
A^{42} B^{48} \\
A^{43} B^{48} \\
A^{47} B^{47} \\
A^{49} B^{48} \\
A^{51} B^{51}\end{array}$ & $\begin{array}{l}A_{4-7} \\
A_{1-8} \\
A_{1-1} \\
A_{2-6} \\
A_{4-6} \\
A_{3-4} \\
A_{2-3} \\
A_{2-2}\end{array}$ & $\begin{array}{c}\text { unknown } \\
\mathrm{B}_{8-2} \\
\mathrm{~B}_{2-2} \\
\mathrm{~B}_{1-1} \\
\mathrm{~B}_{4-1} \\
\text { unknown } \\
\text { ", }\end{array}$ \\
\hline
\end{tabular}

Note-Different incompatibility factors are indicated by a superscript and different alleles by subscripts.

provide a common genetic background against which the effects of the various combinations of incompatibility factors could be assessed. Compatible progeny from the first cross were again crossed with 845 and the process repeated for seven successive generations. The particular combinations of $\mathrm{A}$ and $\mathrm{B}$ factors required were produced by crossing the appropriate pairs of these derived isogenic strains.

Some early tests were carried out with the original heterozygous stocks and the results from these will also be described.

\section{(ii) Mating procedure}

All dimon matings were made on migration complete medium (Snider and Raper, $195^{8}$ ) in $15 \mathrm{~cm}$. plates at $28^{\circ} \mathrm{C}$. The monokaryotic mycelium was inoculated first. After 48 hours, a small inoculum of dikaryotic medium was planted on the growing fringe of the monokaryotic mate. Hyphæ containing the new dikaryons were present within 72 hours.

\section{(iii) Isolation procedure}

An agar block bearing hyphæ of the new dikaryotic mycelium was transferred to fruiting medium (Snider and Raper, 1958). Mature fruit bodies were produced within ten days. Spores from a fruit body were plated and after 24 hours, sixteen germinating spores were isolated. 


\section{(iv) Progeny testing}

The sixteen monokaryotic mycelia, each derived from one spore were individually mated with six tester strains. The three testers for the A factors were so constituted that each $\mathrm{A}$ factor represented in the original dimon mating was coupled with a $B$ factor which was not present in any nucleus of the mated strains. Incompatibility with these testers therefore occurred as a result of common A factors. The B factors were determined on a comparable basis.

\section{(v) Design of dimon matings}

The dimon matings involving the isogenic strains and some of the original heterozygous stocks were planned so that the B factors were constant throughout a series. In the majority of tests they were selectively neutral, the B factor of the monokaryon being doubly heterozygous with both the B factors in the dikaryon. Dikaryons with reciprocal combinations of A and B factors were always tested with each monokaryotic strain thus providing an additional check on any interference by the B factors.

TABLE 2

Data from matings with isogenic strains

\begin{tabular}{|c|c|c|c|c|c|}
\hline \multirow{2}{*}{$S_{1}$} & Dikaryons & \multicolumn{2}{|c|}{$A_{1-1} B_{3-2}+A_{2-3} B_{1-1}$} & \multicolumn{2}{|c|}{$A_{1-1} B_{1-1}+A_{2-3} B_{3-2}$} \\
\hline & $\begin{array}{l}\text { Monokaryons } \\
\text { (a) } \mathrm{A}_{3-4} \mathrm{~B}_{4-4} \\
\text { (b) } \mathrm{A}_{1-8} \mathrm{~B}_{4-4} \\
\text { (c) } \mathrm{A}_{2-2} \mathrm{~B}_{4-4}\end{array}$ & $\begin{array}{c}16 \\
4 \\
12(2)\end{array}$ & $\begin{array}{l}20(\mathrm{I}) \\
10(\mathrm{I}) \\
6\end{array}$ & $\begin{array}{r}13 \\
6 \\
16\end{array}$ & $\begin{array}{r}10(1) \\
21(3) \\
6(I)\end{array}$ \\
\hline \multirow{2}{*}{$\mathrm{S}_{2}$} & Dikaryons & \multicolumn{2}{|c|}{$\mathrm{A}_{3-4} \mathrm{~B}_{4-4}+\mathrm{A}_{2-3} \mathrm{~B}_{1-1}$} & \multicolumn{2}{|c|}{$\mathrm{A}_{3-4} \mathrm{~B}_{1-1}+\mathrm{A}_{2-3} \mathrm{~B}_{4-4}$} \\
\hline & $\begin{array}{l}\text { Monokaryons } \\
\text { (a) } \mathrm{A}_{1-1} \mathrm{~B}_{2-2} \\
\text { (b) } \mathrm{A}_{3-5} \mathrm{~B}_{2-2} \\
\text { (c) } \mathrm{A}_{2-2} \mathrm{~B}_{2-2}\end{array}$ & $\begin{array}{l}14(1) \\
6 \\
13\end{array}$ & $\begin{array}{c}18 \\
17(3) \\
3\end{array}$ & $\begin{array}{c}18(1) \\
o \\
15(2)\end{array}$ & $\begin{array}{r}10 \\
11 \\
5\end{array}$ \\
\hline \multirow{2}{*}{$\mathrm{S}_{3}$} & Dikaryons & \multicolumn{2}{|c|}{$\mathrm{A}_{1-1} \mathrm{~B}_{3-2}+\mathrm{A}_{3-5} \mathrm{~B}_{2-2}$} & \multicolumn{2}{|c|}{$A_{1-1} B_{2-2}+A_{3-5} B_{3-2}$} \\
\hline & $\begin{array}{l}\text { Monokaryons } \\
\text { (a) } \mathrm{A}_{-48} \mathrm{~B}_{1-1} \\
\text { (b) } \mathrm{A}_{1-8} \mathrm{~B}_{1-1} \\
\text { (c) } \mathrm{A}_{3-4} \mathrm{~B}_{1-1}\end{array}$ & $\begin{array}{r}18(4) \\
3(I) \\
42(1)\end{array}$ & $\begin{array}{l}23 \\
33(\mathrm{I}) \\
I I\end{array}$ & $\begin{array}{c}24(3) \\
8(I) \\
36\end{array}$ & $\begin{array}{r}23(1) \\
46(2) \\
7(1)\end{array}$ \\
\hline \multirow{2}{*}{$\mathrm{S}_{4}$} & Dikaryons & \multicolumn{2}{|c|}{$\mathrm{A}_{2-2} \mathrm{~B}_{3-2}+\mathrm{A}_{4-6} \mathrm{~B}_{2-2}$} & \multicolumn{2}{|c|}{$\mathrm{A}_{2-2} \mathrm{~B}_{2-2}+\mathrm{A}_{4-6} \mathrm{~B}_{3-2}$} \\
\hline & $\begin{array}{l}\text { Monokaryons } \\
\text { (a) } \mathrm{A}_{3-5} \mathrm{~B}_{1-1} \\
\text { (b) } \mathrm{A}_{2-3} \mathrm{~B}_{1-1} \\
\text { (c) } \mathrm{A}_{4-7} \mathrm{~B}_{1-1}\end{array}$ & $\begin{array}{l}19(2) \\
14(1) \\
29(1)\end{array}$ & $\begin{array}{l}23(2) \\
30 \\
17\end{array}$ & $\begin{array}{l}14 \\
19 \\
35(4)\end{array}$ & $\begin{array}{l}12 \\
41(3) \\
12\end{array}$ \\
\hline
\end{tabular}

Note-Numbers under dikaryotic nuclear genotypes represent the number of new dikaryons in which a nucleus with such a genotype was associated with a nucleus from the monokaryon. Numbers in brackets represent recombinant nuclei having the A factor of one nucleus of the parental dikaryon and the B factor of the other. They are classified according to their A factor. When the new dikaryons have nuclei with an A allele in common the numbers are in italics. 
The terms $A$ and $B$ factors are used when reference is made to the incompatibility super-genes. The terms $A$ and $B$ alleles refer to the sub-units of which $A$ and $B$ factors are composed.

\section{RESULTS}

(I) Data from isogenic strains

The detailed results of four series of dimon matings $\left(\mathrm{S}_{\mathrm{I}}, \mathrm{S}_{2}, \mathrm{~S}_{3}\right.$ and $\left.\mathrm{S}_{4}\right)$ are assembled in table 2. The B factors are constant and selectively neutral in all these matings. In each series three monokaryotic genotypes $(a, b$ and $c$ ) were mated with the same pair of

TABLE 3

Data from dimon matings in which the $A$ and $B$ factors are doubly heterozygous in respect of their constituent alleles

\begin{tabular}{|c|c|c|c|c|}
\hline & \multicolumn{2}{|c|}{ A factors } & \multicolumn{2}{|c|}{ B factors } \\
\hline & Monokaryon & Dikaryon & Monokaryon & Dikaryon \\
\hline Sı $a$ & $\ddot{A_{3-4}}$ & $\begin{array}{c}A_{1-1}+A_{2-3} \\
29: 32\end{array}$ & $\dddot{B_{4-4}}$ & $\begin{array}{c}B_{3-2}+B_{1-1} \\
27: 34\end{array}$ \\
\hline $\mathbf{S}_{2} a$ & $\dddot{A_{1-1}}$ & $\begin{array}{c}A_{3-4}+A_{2-3} \\
34: 29\end{array}$ & $\ldots$ & $\begin{array}{c}B_{1-A}+B_{1-1} \\
26: 37\end{array}$ \\
\hline $\mathrm{S}_{3} a$ & $\dddot{A_{4-6}}$ & $\begin{array}{c}A_{1-1}+A_{3-5} \\
49^{\prime}: 47\end{array}$ & $\dddot{B_{1-1}}$ & $\begin{array}{c}B_{3-2}+B_{2-2} \\
44: 52\end{array}$ \\
\hline $\mathrm{S}_{4} a$ & $\ldots$ & $\begin{array}{c}A_{2-2}+A_{4-6} \\
35: 37\end{array}$ & 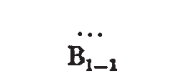 & $\begin{array}{c}B_{3-2}+B_{2-2} \\
33: 39\end{array}$ \\
\hline
\end{tabular}

Note.-The data for A and B factors are separated. The numbers under each dikaryotic nuclear genotype represent the total number of new dikaryons in which a nucleus with this genotype was associated with a nucleus from the monokaryon. The observed deviations from the expected I : I ratios are not statistically significant at the 5 per cent. level.

dikaryons. In every case, $a$ is a monokaryon in which the $\mathrm{A}$ factor is doubly heterozygous with both the A factors in the dikaryon. The data from these mating are analysed in table 3 and it is obvious that not only are both the new dikaryotic genotypes recovered but there is is also good agreement with the expected I:I ratio in respect of combinations of both $\mathrm{A}$ and $\mathrm{B}$ factors.

$b$ and $c$ monokaryons have A factors in which one of the alleles is also present in one A factor of the dikaryon. The data from these matings are analysed in table 4. The alternate combinations of $B$ factors in the new dikaryons occur in a I:I ratio when the results obtained with the reciprocal dikaryons are considered together. The alternate pairs of $\mathrm{A}$ factors in the new dikaryons are however unequal in numbers. In every case there is a highly significant deficiency of new dikaryons in which the A factors have a common allele. 
TABLE 4

Data from dimon matings in which the $A$ factors of the monokaryons have an allele in common with one $A$ factor of the dikaryon

\begin{tabular}{|c|c|c|c|c|}
\hline & \multicolumn{2}{|c|}{ A factors } & \multicolumn{2}{|c|}{ B factors } \\
\hline & Monokaryon & Dikaryon & Monokaryon & Dikaryon \\
\hline $\begin{array}{l}S_{1} b \\
\text { Sic }\end{array}$ & $\begin{array}{l}\dddot{A_{1-8}} \\
A_{2-2}\end{array}$ & $\begin{array}{c}\mathrm{A}_{1-1}+\mathrm{A}_{2-3} \\
10: 35 \\
30: 13\end{array}$ & $\begin{array}{l}\ldots \\
B_{4-4} \\
B_{4-4}\end{array}$ & $\begin{array}{c}B_{3-2}+B_{1-1} \\
26: 19 \\
18: 25\end{array}$ \\
\hline $\begin{array}{l}\mathrm{S}_{2 b} b \\
\mathbf{S}_{2 c}\end{array}$ & $\begin{array}{l}\dddot{\ldots} \\
\mathrm{A}_{3-5} \\
\mathrm{~A}_{2-2}\end{array}$ & $\begin{array}{c}\mathrm{A}_{3-4}+\mathrm{A}_{2-3} \\
6: 3^{\mathrm{I}} \\
30: 8\end{array}$ & $\begin{array}{l}\dddot{0} \\
B_{2-2} \\
B_{2-2}\end{array}$ & $\begin{array}{c}B_{4-1}+B_{1-1} \\
20: 17 \\
20: 18\end{array}$ \\
\hline $\begin{array}{l}\mathrm{S}_{3 b} b \\
\mathrm{~S}_{3^{c}}\end{array}$ & $\begin{array}{l}\ddot{A_{1-8}} \\
A_{3-4}\end{array}$ & $\begin{array}{c}\mathbf{A}_{1-1}+\mathbf{A}_{\mathbf{3 - 6}} \\
13: 82 \\
79: 19\end{array}$ & $\begin{array}{l}\cdots \\
\mathrm{B}_{1-1} \\
\mathrm{~B}_{1-1}\end{array}$ & $\begin{array}{c}B_{3-2}+B_{2-2} \\
51: 44 \\
49: 49\end{array}$ \\
\hline $\begin{array}{l}\mathrm{S}_{4 b} b \\
\mathrm{~S}_{4 c}\end{array}$ & $\begin{array}{l}\ddot{A_{2-3}} \\
A_{4-7}\end{array}$ & $\begin{array}{c}A_{2-2}+A_{4-8} \\
34: 74 \\
69: 29\end{array}$ & $\begin{array}{l}\ddot{B_{1-1}} \\
B_{1-1}\end{array}$ & $\begin{array}{c}B_{3-2}+B_{2-2} \\
55: 53 \\
45: 53\end{array}$ \\
\hline
\end{tabular}

Note.-The data for A and B factors are separated.

The numbers under each dikaryotic nuclear genotype represent the total numbers of new dikaryons in which a nucleus with this genotype was associated with a nucleus from the monokaryon. italics.

Where the new dikaryons have A factors with an allele in common the numbers are in

The observed deviations from the expected I : I ratios for A allele pairs are statistically significant at the I per cent. level. level.

The deviations from 1 : 1 ratios for $B$ allele pairs are not significant at the 5 per cent.

\section{(ii) Data from heterozygous stocks}

The clear results with isogenic strains suggest that when the $B$ factors in compatible dimon matings are selectively neutral, the control of selection in the establishment of new dikaryons rests with the A factors and operates in favour of those dikaryons which are doubly heterozygous at the A loci. The results of dimon matings in which the strains are heterozygous reveal that this interpretation is oversimplified. Since heterozygosity of mates is the rule in nature and dimon matings are probably an important means of establishing new dikaryons, it is of interest to see how the matings between heterozygotes behave.

The results are assembled in table 5 and analysed in table 6 . In the series $\mathrm{S}_{7}$, the $\mathrm{B}$ alleles are constant throughout and selectively neutral. In $\mathrm{S}_{5}$ and $\mathrm{S} 6$ the $\mathrm{B}$ alleles in the dikaryons are constant but they vary in the monokaryons. In addition, some $\mathrm{B}$ factors involved in the latter two series have unknown alleles and may therefore exercise some selective effect.

There are five matings in these series which are of particular interest. Reference to table 5 shows that $\mathrm{S}_{5} b$ is behaving anomalously. 
There are no new dikaryons with common A alleles recovered in one of the matings but when the same monokaryon is tested with the second dikaryon in which the A and B factors are reciprocally combined there is actually a majority of new dikaryons in which the A factors have an allele in common. There are two B factors of unknown constitution involved here, $\mathrm{B}^{9}$ and $\mathrm{B}^{49}$. Reference to the analysed

TABLE 5

Data from matings with heterozygous strains

\begin{tabular}{|c|c|c|c|c|c|}
\hline \multirow{2}{*}{$\mathrm{S}_{5}$} & Dikaryons & \multicolumn{2}{|c|}{$A_{1-1} B_{3-2}+A_{2-3} B^{49}$} & \multicolumn{2}{|c|}{$A_{1-1} B^{4 \theta}+A_{2-3} B_{3-2}$} \\
\hline & $\begin{array}{l}\text { Monokaryons } \\
\text { (a) } \mathrm{A}_{3-4} \mathrm{~B}_{4-1} \\
\text { (b) } \mathrm{A}_{1-8} \mathrm{~B}^{9} \\
\text { (c) } \mathrm{A}_{2-2} \mathrm{~B}^{51}\end{array}$ & $\begin{array}{l}15 \\
16(x) \\
13\end{array}$ & $\begin{array}{r}12 \\
12(1) \\
I(I)\end{array}$ & $\begin{array}{c}14(1) \\
0 \\
15\end{array}$ & $\begin{array}{r}18 \\
29 \\
5\end{array}$ \\
\hline \multirow{2}{*}{ S6 } & Dikaryons & \multicolumn{2}{|c|}{$\mathrm{A}_{3-4} \mathrm{~B}_{4-4}+\mathrm{A}_{2-3} \mathrm{~B}^{4 \theta}$} & \multicolumn{2}{|c|}{$A_{3-4} B^{49}+A_{2-3} B_{4-4}$} \\
\hline & $\begin{array}{l}\text { Monokaryons } \\
\text { (a) } \mathrm{A}_{1-1} \mathrm{~B}_{3-2} \\
\text { (b) } \mathrm{A}_{3-5} \mathrm{~B}_{2-2} \\
\text { (c) } \mathrm{A}_{2-2} \mathrm{~B}^{51}\end{array}$ & $\begin{array}{l}3 \\
6 \\
17(2)\end{array}$ & $\begin{array}{l}17 \\
15(1) \\
2\end{array}$ & $\begin{array}{r}9 \\
I(2) \\
22(1)\end{array}$ & $\begin{array}{l}19(1) \\
14 \\
5\end{array}$ \\
\hline \multirow{2}{*}{$\mathrm{S}_{7}$} & Dikaryons & \multicolumn{2}{|c|}{$\mathrm{A}_{1-1} \mathrm{~B}_{3-2}+\mathrm{A}_{3-5} \mathrm{~B}_{2-2}$} & \multicolumn{2}{|c|}{$A_{1-1} B_{2-2}+A_{3-5} B_{3-2}$} \\
\hline & $\begin{array}{l}\text { Monokaryons } \\
\text { (a) } \mathrm{A}_{4-6} \mathrm{~B}_{1-1} \\
\mathrm{~A}_{2-3} \mathrm{~B}_{1-1} \\
\mathrm{~A}_{4-7} \mathrm{~B}_{1-1} \\
\mathrm{~A}_{2-2} \mathrm{~B}_{1-1} \\
\text { (b) } \mathrm{A}_{1-8} \mathrm{~B}_{1-1} \\
\text { (c) } \mathrm{A}_{3-4} \mathrm{~B}_{1-1}\end{array}$ & $\begin{array}{l}16(2) \\
14(1) \\
20 \\
39 \\
21(2) \\
24(2)\end{array}$ & $\begin{array}{l}25 \\
19 \\
5 \\
23(2) \\
15 \\
15\end{array}$ & $\begin{array}{r}19(1) \\
27 \\
6(1) \\
46(1) \\
21 \\
39\end{array}$ & $\begin{array}{r}13(1) \\
17(2) \\
24 \\
19(1) \\
9(1) \\
18\end{array}$ \\
\hline
\end{tabular}

Note.-Numbers under dikaryotic nuclear genotypes represent the number of new dikaryons in which a nucleus with such a genotype was associated with a nucleus from the monokaryon. Numbers in brackets represent recombinant nuclei. They are classified according to their $\mathrm{A}$ factor. When the new dikaryons have nuclei with an allele in common the numbers are in italics.

results in table 6 shows that there is a significant shortage of $B^{9}+B^{49}$ dikaryons. If $\mathrm{B}^{9}$ and $\mathrm{B}^{49}$ have a common allele, the unusual behaviour of $\mathrm{S}_{5} b$ would be explained.

$\mathrm{S} 6 a$ is another anomalous case. The deviation from a $\mathrm{I}: \mathrm{I}$ ratio in unexpected because the $A$ and $B$ factors (with the possible exception of $\mathrm{B}^{49}$ ) have no common alleles. Table 6 shows that this inconsistency is not due to the $B$ factors but rather to a shortage of new dikaryons, including $\mathrm{A}_{1-1}$ and $\mathrm{A}_{3-4}$. This kind of deviation is not consistent with the established pattern and must be caused by genes other than the incompatibility factors, A and B. The same may be said of the third and fourth members, of $\mathrm{S}_{7} a$ where the alleles of all the A and B factors are known to be different. $\mathrm{S}_{7} b$ in particular, demonstrates the influence 
of these extra-incompatibility factors. The mating type alleles in this cross are identical with those of $\mathrm{S}_{3} b$, the monokaryon and a nucleus of the dikaryon having an $\mathrm{A}$ allele in common. In the isogenic strains this fact causes a shortage of $A_{1-8}+A_{1-1}$ dikaryons, while in heterozygotes the result is reversed although the deviation from a I:I ratio is not significant.

TABLE 6

\begin{tabular}{|c|c|c|c|c|}
\hline & \multicolumn{2}{|c|}{ A factors } & \multicolumn{2}{|c|}{ B factors } \\
\hline & Monokaryon & Dikaryon & Monokaryon & Dikaryon \\
\hline $\begin{array}{l}\mathbf{S}_{5} a \\
\mathbf{S}_{5 b} \\
\mathbf{S}_{5^{c}}\end{array}$ & $\begin{array}{l}\dddot{A_{3-4}} \\
A_{1-8} \\
A_{2-2}\end{array}$ & $\begin{array}{c}\mathrm{A}_{1-1}+\mathrm{A}_{2-3} \\
30: 30 \\
17: 4^{2} \\
28: 7\end{array}$ & $\begin{array}{l}\ddot{B}_{-} \\
\mathrm{B}^{9} \\
\mathrm{~B}^{\Delta 1}\end{array}$ & $\begin{array}{c}\mathrm{B}_{2-3}+\mathrm{B}^{4 \vartheta} \\
34: 26 \\
46: 13 \\
19: 16\end{array}$ \\
\hline $\begin{array}{l}\text { S6a } \\
\text { S } 6 b \\
\text { S } 6 c\end{array}$ & $\begin{array}{l}\dddot{A_{1-1}} \\
A_{3-5} \\
A_{2-2}\end{array}$ & $\begin{array}{c}\dot{A}_{3-4}+A_{2-3} \\
12: 37 \\
9: 30 \\
42: 7\end{array}$ & $\begin{array}{l}\dddot{\mathrm{B}_{3-2}} \\
\mathrm{~B}_{2-2} \\
\mathrm{~B}^{51}\end{array}$ & $\begin{array}{c}B_{4-4}+B^{4 \theta} \\
22: 27 \\
23: 16 \\
23: 26\end{array}$ \\
\hline $\begin{array}{l}S_{7 b} \\
S_{7 c}\end{array}$ & $\begin{array}{l}\dddot{1} \\
\mathrm{~A}_{4-8} \\
\mathrm{~A}_{2-3} \\
\mathrm{~A}_{4-7} \\
\mathrm{~A}_{2-2} \\
\mathrm{~A}_{1-8} \\
\mathrm{~A}_{3-4}\end{array}$ & $\begin{array}{c}A_{1-1}+A_{3-5} \\
38: 39 \\
42: 38 \\
27: 29 \\
86: 45 \\
44: 25 \\
65: 33\end{array}$ & $\begin{array}{l}\dddot{B_{1-1}} \\
\mathrm{~B}_{1-1} \\
\mathrm{~B}_{1-1} \\
\mathrm{~B}_{1-1} \\
\mathrm{~B}_{1-1} \\
\mathrm{~B}_{1-1}\end{array}$ & $\begin{array}{c}\mathrm{B}_{\mathbf{3 - 2}}+\mathrm{B}_{\mathbf{2 - 2}} \\
30: 47 \\
31: 49 \\
45: 11 \\
61: 70 \\
30: 39 \\
4^{2}: 56\end{array}$ \\
\hline
\end{tabular}

Note.-Data for A and B factors are separated. Where the new dikaryons have A factors with an allele in common the numbers are in italics.

Despite these irregularities in behaviour when heterozygous stocks are used in compatible dimon matings, selection favouring dikaryons with doubly heterozygous $\mathrm{A}$ alleles may still operate. It would account for the deviation from a $\mathrm{I}: \mathrm{I}$ ratio observed in $\mathrm{S}_{5}$, $\mathrm{S} 6 b$ and $c$, and in $\mathrm{S} 7 c$.

\section{DISCUSSION}

The incompatibility system in $S$. commune bars pairs of homozygous nuclei from association in a dikaryon. The barrier is absolute for nuclei which are homozygous for the A alleles, or homozygous for the $\mathrm{B}$ alleles or homozygous for both. On this basis, permissible dikaryons fall into four categories: (I) those which are doubly heterozygous in respect of the $A$ and $B$ alleles, e.g. $A_{1-1} B_{1-1}+A_{2-2} B_{2-2}$, (2) those which are doubly heterozygous in respect of the $A$ alleles but have one $B$ allele in common, e.g. $A_{1-1} B_{1-1}+A_{2-2} B_{1-2}$, (3) those which are doubly heterozygous in respect of the $B$ alleles but have one $A$ allele in common e.g. $A_{1-1} B_{1-1}+A_{1-2} B_{2-2}$, and (4) those which have one $A$ and one $B$ allele in common, e.g. $A_{1-1} B_{1-1}+A_{1-2} B_{1-2}$. No difference in the degree of compatibility in these four classes of dikaryon can be detected in matings between monokaryotic strains. 
Compatible dimon matings, in effect, offer a monokaryon choice between two possible partners with which to form a new dikaryon. This reveals a second form of selection at work in determining the genotype of the dikaryon; selection which discriminates between compatible nuclei. In the competitive conditions set up by a fully compatible dimon mating, the two new combinations of nuclei may show different degrees of success in establishing a dikaryotic mycelium. The data so far indicate that those dikaryons which have maximum heterozygosity in respect of their incompatibility alleles are in the main, more successful than those which are only partially heterozygous.

Where the choice rests between a dikaryon with a common B allele or a dikaryon with a common A allele, it appears that heterozygosity of the B factors may be the first criterion of selection. For instance the data of Raper and Ellingboe ( 1962 ) include the results from a dimon mating $\left(\mathrm{A}_{1-1} \mathrm{~B}_{3-2}+\mathrm{A}_{3-4} \mathrm{~B}_{4-4} \times \mathrm{A}_{3-5} \mathrm{~B}_{2-2}\right.$. Of the new dikaryons recovered, thirty-two were doubly heterozygous for their $\mathrm{A}$ alleles, i.e. $A_{1-1} B_{3-2}+A_{3-5} B_{2-2}$ as against two hundred and seventy-four which were doubly heterozygous for their $B$ alleles, i.e. $A_{3-4} B_{4-4}+A_{3-5} B_{2-2}$. Only when the $B$ factors are selectively neutral is selection based on the relationship between the $\mathrm{A}$ alleles.

It is clear that the incompatibility barrier can no longer be regarded as the sole mechanism determining the dikaryotising ability of a pair of nuclei. There are at least two other mechanisms which can be shown to operate in matings between monokaryons and dikaryons and which depend upon the internal organisation of the incompatibility factors themselves. These refinements of the basic out-breeding system may apply generally in the Basidiomycetes. S. commune is not alone in having complex incompatibility genes. They have been reported in Pleurotus oesteatus (Terakawa, 1960), in Coprinus lagopus (Day, 1960) and in Collybia velutipes (Takemaru, 196I). In these species too the incompatibility factors can exist in dikaryons in varying degrees of heterozygosity and so provide the conditions for the discrimination between compatible nuclei observed on $S$. commune.

\section{SUMMARY}

I. There is discrimination between nuclei in the establishment of a dikaryon in fully compatible dimon (dikaryon $\times$ monokaryon) matings in Schizophyllum commune.

2. The discrimination in isogenic strains is controlled by two incompatibility super-genes, $\mathrm{A}$ and $\mathrm{B}$, which can exist in dikaryons in varying degrees of heterozygosity.

3. In those dimon matings where the B super-genes are selectively neutral selection always favours dikaryons with greater heterozygosity of the A super-genes.

4. This principle it is suggested may apply generally in the Basidiomycetes. 
5. In non-isogenic strains, genes other than the incompatibility factors may also control selection.

Acknowledgments.-My thanks are due to Professor J. R. Raper who supplied the strains of Schizophyllum and in whose laboratory these experiments were started. I am also indebted to Miss J. Barker for her valuable technical assistance.

\section{REFERENCES}

CROWE, L. K. I 960 . The exchange of genes between nuclei of a dikaryon. Heredity, $15,397-405$.

DAY, P. R. 1960. The structure of the A mating type locus in Coprinus lagopus. Genetics, 45, 641-650.

KimURA, K. 1958. Diploidisation in the Hymenomycetes. II. Nuclear behaviour in the Buller Phenomenon. Biol. F. Okayama Univ., 4, I-59.

RAPER, J. R., BAXTER, M. G., AND MIDDLETON, R. B. 1958. The genetic structure of the incompatibility factors in Schizophyllum commune. Proc. Nat. Acad. Sci. (U.S.), $46,833-84^{2}$.

Raper, J. R., ANd ellingboe, A. H. 1962. The Buller Phenomenon in Schizophyllum commune : nuclear selection in fully compatible dikaryotic-homokaryotic matings. Amer. F. Bot., 49, 454-459.

SNIDER, P. J., AND RAPER, J. R. 1958. Nuclear migration in the basidiomycete, Schizophyllum commune. Amer. 7. Bot., 45, 538-546.

takemarU, T. 1961. Genetical studies on fungi. X. The mating system in Hymenomycetes and its genetical mechanism. Biol. 7. Okayama Univ., 7, 133-211.

terakawa, H. 1960. The incompatibility factors in Pleurotus ostreatus. Sci. Papers Coll. Gen. Educ. Univ. Tokyo, so, 65-71. 